\begin{tabular}{cc|c}
\hline Tar. Bil. Der. & Journal of Agricultural Sciences \\
& $\begin{array}{c}\text { Dergi web sayfası: } \\
\text { www.agri.ankara.edu.tr/dergi }\end{array}$ & Journal homepage: \\
& www.agri.ankara.edu.tr/journal
\end{tabular}

\title{
Borçka Barajı Rezervuarında Yeni Oluşmuş Bir Sediment Birikim Sahasındaki Penetrasyon Direnç Değerlerinin Uzaysal Dağılımı
}

\author{
Bülent TURGUT ${ }^{a}$, Mehmet ÖZALP ${ }^{a}$, Taşkın ÖZTAŞ ${ }^{b}$ \\ aArtvin Çoruh Üniversitesi, Orman Fakültesi, Orman Mühendisliği Bölümü, 08000, Artvin, TÜRKIYE

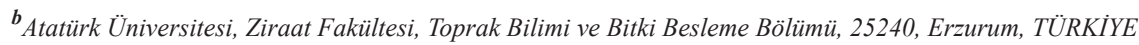

\section{ESER BILGISİ}

Araştırma Makalesi DOI: 10.15832/ankutbd.447604

Sorumlu Yazar: Bülent TURGUT, E-posta: bturgut@artvin.edu.tr, Tel: +90 (533) 6487188

Geliş Tarihi: 31 Aralık 2014, Düzeltmelerin Gelişi: 25 Aralık 2015, Kabul: 28 Aralık 2015

\begin{abstract}
ÖZET
Bu çalışma, Borçka Barajı rezervuarında yeni oluşmuş sediment birikim sahalarından birindeki penetrasyon direnci (PD) değerlerinin yatay ve düşey doğrultudaki uzaysal değişkenliğinin belirlenmesi amacıyla yürütülmüştür. Araştırma sahasında $50 \mathrm{~m}$ x $10 \mathrm{~m}$ aralıklarla 91 grid oluşturulmuş ve her bir gridde $80 \mathrm{~cm}$ 'lik derinlik boyunca $10 \mathrm{~cm}$ 'lik artışlarla belirlenen 8 katmanın PD değerleri ölçülmüştür. Tüm katmanlarda PD'nin uzaysal değişkenliği jeoistatistiksel yöntemlerle belirlenmiştir. Her bir katman için PD'ne ait semivaryogramlar oluşturulmuş ve buna bağlı olarak krigleme haritaları üretilmiştir. Çalışma sonunda PD'nin yüzey katmanında $(0-10 \mathrm{~cm})$ en yüksek değeri aldığı $(0.75 \mathrm{MPa})$ ve derinlikle beraber kademeli olarak azaldığı ortaya konulmuştur. Tanımlayıcı istatistikler ve jeoistatistiksel analiz sonuçları, çevresel faktörlerden önemli seviyede etkilenen ve ölçüm zamanında daha kuru olan yüzey katmanındaki PD değerlerinin diğer katmanlara nazaran daha değişken olduğunu göstermiştir. PD’nin uzaysal değişkenliği, ilgili semivaryogramların sill, nugget ve range değerleri ile krigleme yoluyla üretilen yüzey haritaları tüm katmanlarda farklılık göstermiştir. Jeoistatistiksel range değerlerinin en kısası (40.8 m) yüzey katmanında $(0-10 \mathrm{~cm})$ ve en uzunu $(173.3 \mathrm{~m})$ ise ikinci katmanda $(21-30 \mathrm{~cm})$ hesaplanmıştır. Bunun yanında en yüksek nugget etki (\% 44) üçüncü katmanda $(21-30 \mathrm{~cm})$ ve en düşügü ise (\% 13) ikinci katmanda gerçekleşmiştir. Benzer çalışmaların farklı birikim sahalarında ve daha fazla değişkenle tekrar edilmesinin, bu alanlardaki uzaysal değişkenliğin gelişiminde ve derecesinde etkili olan mekanizmaların anlaşılmasında yararlı olacağı düşünülmektedir.
\end{abstract}

Anahtar Kelimeler: Jeoistatistik; Krigleme; Sediment; Semivaryogram; Sıkışma

\section{Spatial Distribution of Penetration Resistance in a Recently Deposited Sediment Area within the Borçka Dam Reservoir}

\author{
ARTICLE INFO \\ Research Article \\ Corresponding Author: Bülent TURGUT, E-mail: bturgut@artvin.edu.tr, Tel: +90 (533) 6487188 \\ Received: 31 December 2014, Received in Revised Form: 25 December 2015, Accepted: 28 December 2015
}

\section{ABSTRACT}

This study was conducted to analyze vertical and horizontal spatial variability of penetration resistance (PR) in recently deposited sediments at Borçka Dam reservoir. Ninety-one grids with $50 \mathrm{~m}$ by $10 \mathrm{~m}$ were located and PR was measured 
to a depth $80 \mathrm{~cm}$ by $10 \mathrm{~cm}$ increment ( 8 layers) within each grid. Spatial variation of PR was assessed by geostatistical techniques in all 8 layers. Semivariograms of PR were constructed for all the layers and corresponding kriging maps were built. The PR values were greater in surface layer $(0-10 \mathrm{~cm})$ and gradually decreased by depth. Mean PR was greatest $(0.747 \mathrm{MPa})$ in surface layer and lowest $(0.413 \mathrm{MPa})$ in $61-70 \mathrm{~cm}$ (layer 7$)$. Results from exploratory statistics and geostatistical analyses showed that the PR values were more variable in surface layer compared to those in deeper layers due to that the surface layer was drier at the sampling and that affected by environmental factors in a greater extent. All the studied layers exhibited differences in spatial variation of PR as sill, nugget, and range values of corresponding semivariograms and kriging-predicted surface maps showed. The shortest geostatistical range $(40.8 \mathrm{~m})$ occurred of surface layer while longest $(173.3 \mathrm{~m})$ occurred for second layer $(11-20 \mathrm{~cm})$. The nugget effect was greatest $(44 \%)$ in third layer $(21-30 \mathrm{~cm})$ while lowest (13\%) in the surface layer. The same study may be repeated with more variables to understand mechanisms behind development and extent of spatial variation in these newly deposited sediments.

Keywords: Compaction; Geostatistics; Kriging; Sediment; Semivariogram

(C) Ankara Üniversitesi Ziraat Fakültesi

\section{Giriş}

İnsan müdahalelerinin söz konusu olmadığı nehirlerde sediment giriş ve çıkışı dengededir (Morris \& Fan 1998). Ancak barajlar gibi nehrin doğal akış rejimini değiştiren yapılar nedeniyle denge bozulmakta, suyun akış hızının ve taşıma gücünün azaldığı rezervuar sahalarında kademeli olarak sediment birikimi gerçekleşmektedir (Bravard et al 2014). Baraj rezervuar sahalarında biriken sedimentler genellikle kum, silt ve kil iriliğindeki parçacıklardan oluşmaktadır (Kamarudin et al 2009).

Sediment birikim sahalarındaki penetrasyon direnci (PD) ölçümleri birikim süresine göre farklılık göstermektedir. Sediment birikiminin ilk aşamasında kil ve silt tanecikleri parçacıklar arası köprü marifetiyle gevşek bir matriks içinde yerleşmektedirler (Morris \& Fan 1998). Fakat zamanla ortama dâhil olan yeni sedimentlerin kendi ağırlıkları nedeniyle oluşturdukları basınç, poroziteyi ve boşluk oranını azaltıp hacim ağırlığını arttırarak PD'nin yükselmesine neden olmaktadır (Arega \& Hayter 2008; Narantsetseg et al 2014).

Rezervuar sahalarında biriken sedimentlerin orijinleri farklı olduğundan sediment özellikleri önemli derecede değişkenlik göstermektedir (Walling \& Moorehead 1989; Morris \& Fan 1998; $\mathrm{Xu}$ 2000). Bu nedenle sediment özelliklerinin istatistiksel anlamda değerlendirilmesinde, bir parametrenin uzaysal dağılımını ve uzaysal davranışını karakterize eden, bu bilgileri kullanarak incelenen değişkenin örneklenen noktalar arasındaki değerini tahmin eden ve tahminleme hatasını en aza indirgemede kullanılabilen jeoistatistiksel analizler tercih edilmektedir (Webster \& Oliver 1992; Cabezas et al 2010; de Groot et al 2011).

Deriner Barajı'nın 2012 yılından itibaren su tutmaya başlaması ile Borçka Barajı rezervuarına ulaşan su miktarında önemli düzeyde azalma meydana gelmiş ve buna bağlı olarak rezervuar sahasının önemli bir kısmında sediment birikim alanları belirgin bir şekilde ortaya çıkmıştır. $\mathrm{Bu}$ birikim sahalarından biri de Çoruh Nehri'nin membaina doğru ve Borçka Barajı'na yaklaşık 20 $\mathrm{km}$ mesafede oluşmuş ve bu durum şimdiye kadar üzerinde çalışılmamış olan yeni sediment birikim sahalarında araştırma yapma firsatı sunmuştur.

$\mathrm{Bu}$ çalışmanın amacı, Borçka Barajı rezervuar sahasında oluşmuş yeni sediment birikim sahalarında PD'nin (i) derinliğe bağlı olarak değişimini incelemek, (ii) uzaysal bağımlılık derecelerini belirlemek ve (iii) dağılım haritalarını oluşturmaktır. Böylece yeni biriken sedimentlerdeki sıkışma süreci hakkında şimdiye kadar literatürde yer almayan bilgilere ulaşılması amaçlanmıştır.

\section{Materyal ve Yöntem}

\section{1. Çalışma alanının genel özellikleri}

Çalışma Çoruh Nehri üzerinde kurulmuş olan Borçka Baraj1 rezervuar alanında oluşan sediment birikim alanlarından birinde yürütülmüştür (Şekil 1). Söz konusu alan Borçka Barajının $20 \mathrm{~km}$ güneyinde ve Artvin şehir merkezi çıkışının $3 \mathrm{~km}$ kuzeyindedir. Çalışma alanının denizden yüksekliği ise yaklaşık 190 m'dir. Çoruh havzası, yılda taşınan yaklaşık 5.8 milyon $\mathrm{m}^{3}$ sediment miktarı ile toprak erozyonunun 
en yoğun olduğu havzalardan birisidir (Sucu \& Dinç 2008). Borçka Barajı'nın 2006 yılından itibaren su tutmaya başlaması ile beraber yaklaşı $10.84 \mathrm{~km}^{2}$ lik bir rezervuar alanı oluşmuştur. Rezervuar sahasındaki sedimentin kaynağını Çoruh havzası boyunca erozyonla taşınan materyal ile yol yapımı ve baraj inşaatı esnasında nehre atılan hafriyat oluşturmaktadır. Çoruh havzasının ortalama eğimi \% 30'un üzerinde olup (Zengin et al 2009; Akınc1 et al 2013; Yavuz Özalp et al 2013) havza sınırları içerisinde oldukça yüksek oranlarda bozuk ormanlar ve çıplak alanlar mevcuttur (Pekal \& Tilki 2010). Çalışma alanındaki sedimentlere ait bazı fiziksel ve kimyasal özellikler incelendiğinde alandaki yaygın tekstür sınıfının killi tın olduğu, pH değerleri bakımından hafif alkalin, organik madde içeriği bakımından düşük ve agregat stabilitesi bakımından ise zayıf sınıfında yer aldığı belirlenmiştir (Çizelge 1).

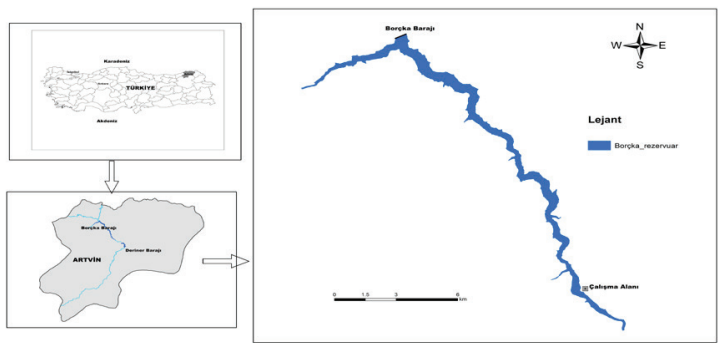

Şekil 1- Borçka Barajı rezervuar sahası ve çalışma alanı

Figure 1- Location of Borcka Dam reservoir and the experimental field

Çizelge 1- Çalışma alanına ait sediment özellikleri $(\mathbf{n}=182)$

Table 1-Sediment properties of the study site $(n=182)$

\begin{tabular}{lrr}
\hline Sediment özelliği & Ortalama & $\begin{array}{r}\text { Değişsenlik } \\
\text { katsayısı (\%) }\end{array}$ \\
\hline Kil (\%) & 35.12 & 44.14 \\
Kum (\%) & 23.53 & 106.16 \\
Silt (\%) & 41.34 & 31.35 \\
pH & 7.71 & 2.00 \\
Organik madde (\%) & 1.06 & 36.11 \\
Agregat stabilitesi (\%) & 17.47 & 67.34 \\
\hline
\end{tabular}

\section{2. Örnekleme yöntemi ve penetrasyon direnç} değerlerinin ölçülmesi

Yaklaşı1k 300 m uzunluğunda ve $120 \mathrm{~m}$ genişliğindeki 3.6 ha'lık çalışma alanı Doğu-Batı ve Kuzey-Güney doğrultularında $50 \mathrm{~m} \mathrm{x} 10$ m'lik gridlere bölünmüş ve gridlerin kesiştiği 91 noktada penetrasyon direnci (PD) ölçülmüştür (Şekil 2). PD'nin belirlenmesinde her $1 \mathrm{~cm}$ 'lik derinlikten ölçüm değeri alabilen bir
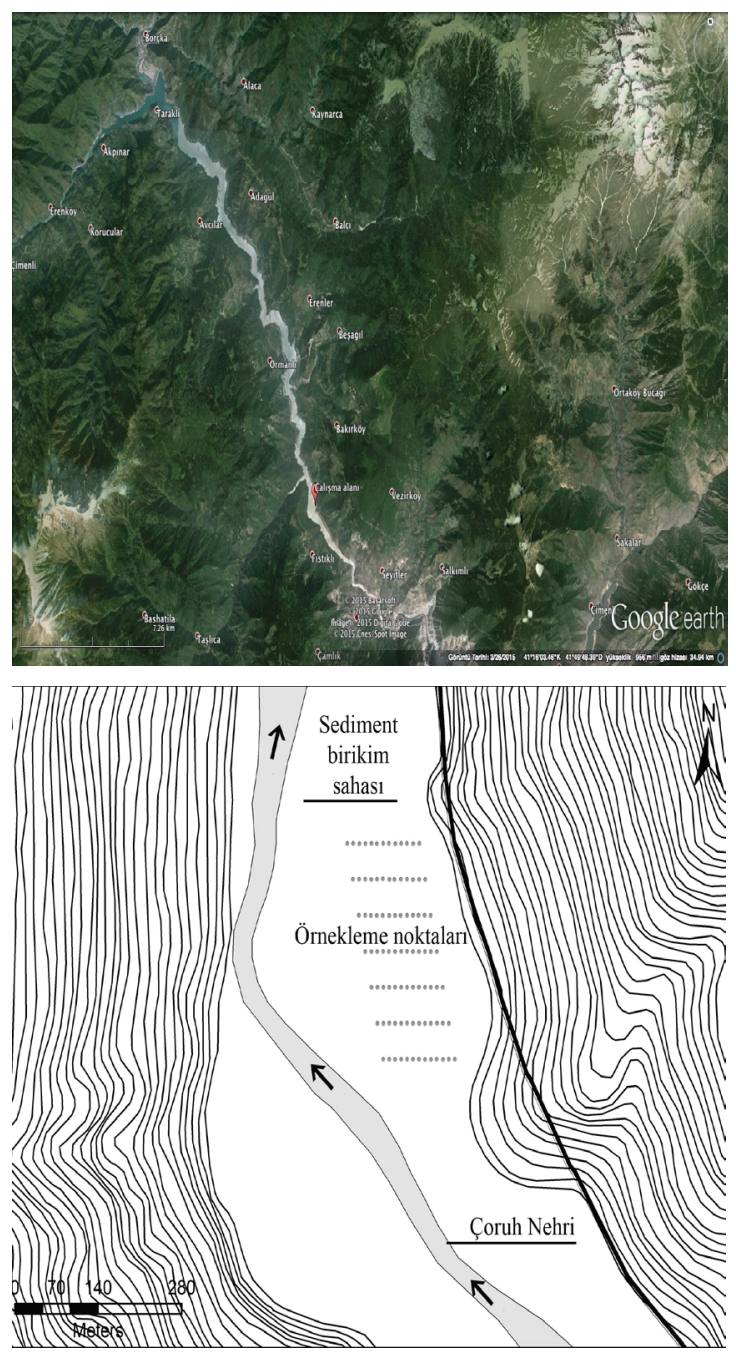

Şekil 2- Çalışma alanının topoğrafyası ve örnekleme noktaları

Figure 2- Topography of the experimental field and location of sampled points 
dijital penetrometre (Eijelkamp Penetrologger) kullanılmıştır. Elde edilen ölçümlerden her bir örnekleme noktası için 0-10 cm, 10-20 cm, 20-30 cm, $30-40 \mathrm{~cm}, 40-50 \mathrm{~cm}, 50-60 \mathrm{~cm}, 60-70 \mathrm{~cm}$ ve $70-80$ cm'lik katmanlar için ortalama PD hesaplanmıştır. Örneklerin tane büyüklük dağılımlarının belirlenmesinde Bouyoucos hidrometre yöntemi (Gee \& Bauder 1986), organik madde içeriğinin belirlenmesinde 1slak yakma yöntemi (Mulvaney 1996), suya dayanıklı agregatların belirlenmesinde Yoder islak eleme yöntemi (Dane et al 2002) ve pH'ların belirlenmesinde ise 1:2.5 sediment:su süspansiyonu kullanılmıştır (Conklin 2005).

\subsection{Tanımlayıcı istatistikler ve jeoistatistiksel yöntemler}

Veri setinde yer alan tüm değerlere tanımlayıcı istatistiksel analizler uygulanmıştır. $\mathrm{Bu}$ amaçla, her bir katman için en düşük ve en yüksek değer, ortalama, standart sapma, çarpıklık ve basıklık değerleri hesaplanmıştır. Bunun yanında verilerin normal dağılıma uygunluklarının belirlenmesinde Shapiro-Wilk W Testi uygulanmıştır. Normal dağılıma uygunluk analizinde artık (residual) değerler kullanılmıştır (Montgomery et al 2012). PD bakımından katmanlar arasındaki farklılığın belirlenmesinde tek yönlü varyans analizi (ANOVA) ve ortalamaların karşılaştırılmasında asgari önem derecesi (LSD) çoklu karşılaştırma testi kullanılmıştır. Uygulanan istatistiksel analizlerde JMP 5.0 yazılımından yararlanılmıştır.

PD'nin her katmandaki uzaysal bağımlılığı, semivaryogram analizi yardımıyla belirlenmiştir. Semivaryogram belli bir h mesafesi ile birbirlerinden ayrılan örnek çiftleri arasındaki varyansın mesafeyle olan ilişkisini göstermektedir. Diğer bir ifade ile semivaryogram, örnekleme çiftleri arasındaki mesafenin bir fonksiyonu olarak uzaysal bağımlılığı tanımlamakta ve matematiksel olarak Eşitlik 1 ile ifade edilmektedir (Journel \& Huijbregts 1978).

$$
\gamma(h)=\frac{1}{2 N(h)} \sum_{i=1}^{N}\left[Z\left(x_{i}\right)-Z\left(x_{i}+h\right)\right]^{2}
$$

Burada; $\gamma(\mathrm{h})$, semivaryans; $N(h), h$, mesafesi ile ayrılan örnek çiftlerinin sayısı; $Z(x i)$, incelenen özelliğin $i$ noktasındaki ölçüm değeri ve $Z(x i+h)$ ise incelenen özelliğin $(\mathrm{i}+\mathrm{h})$ noktasındaki ölçüm değeridir.

Standart bir varyogramın tanımlanmasında üç temel parametre kullanılmaktadır, bunlar; nugget varyans $\left(c_{0}\right)$, sill $\left(c_{0}+c\right)$ ve range (r)'dir. Nugget varyans, örnekleme ölçeğinde açıklanamayan varyasyonu temsil etmektedir. Bu varyans sadece ölçüm hatalarından ve mikro ölçekli varyasyondan kaynaklanmaktadır. Sill, varyogram ile elde edilebilen en yüksek varyans değeridir ve şansa bağlı sürecin varyansını tahmin etmektedir. Range ise örnek çiftlerinin birbirleriyle ilişkili olabilecekleri en yüksek mesafe ya da uzaysal ilişkinin sınırı olarak tanımlanmaktadır.

İncelenen yapının en önemli uzaysal özelliklerini elde etmek için varyogram modellerinden küresel ve üssel modeller deneysel varyogram olarak belirlenmiştir. Bu modeller Eşitlik 2 ve Eşitlik 3'te tanımlanmıştır (Oliver \& Webster 2014).

Küresel model için;

$$
\begin{aligned}
& \gamma_{m}(h)=c_{0}+c\left[\frac{3 h}{2}-\frac{1}{2}\left(\frac{h}{r}\right)^{3}\right] \quad h \leq r \\
& \gamma_{m}(h)=c_{0}+c \quad h>r
\end{aligned}
$$

Eksponansiyel model için;

$$
\gamma_{m}(h)=c_{0}+c\left[1-\exp \left(\frac{-3 h}{a}\right)\right]
$$

Burada; $h=|\mathrm{h}|, \quad$ örnek çiftleri arasındaki mesafeyi (lag); $c_{0}$, nuget varyansı; $c$, uzaysal olarak ilişkilendirilen varyansı ve $r$ ise range değerini ifade etmektedir.

Her bir katman için PD’nin uzaysal dağılımlarının haritalandırılmasında, yakın örnek değerlerinin ağırlıklı ortalamasını esas alarak örneklenmeyen noktaların değerlerini tahmin eden Kriging interpolasyon yöntemi kullanılmıştır (Goovaerts 1999). Bu yöntem Eşitlik 4 ile ifade edilmiştir.

$$
\hat{Z}\left(S_{0}\right)=\sum_{i=1}^{N} \lambda_{i} Z\left(S_{i}\right)
$$

Burada; $Z\left(S_{i}\right)$, incelenen özelliğin $i$ noktasındaki ölçüm değerini; $\lambda_{i}$, $i$ noktasındaki ölçülen değere 
verilmesi gereken ağırlı̆̆ı; $S_{0}$, tahmini yapılan noktayı ve $N$ ise $\hat{Z}\left(S_{0}\right)$ 'nun tahmininde kullanılan komşu veri sayısıdır. Jeoistatistiksel analizlerin uygulanmasında GS+10 yazılımı kullanılmıştır (Gamma Design Software 2014).

\section{Bulgular ve Tartışma}

\subsection{Tanımlayıcı istatistikler}

Veri setinde yer alan değerlere ait ortalama, standart sapma, en düşük ve en yüksek değer ile değişim genişliği değerlerini içeren tanımlayıcı istatistik sonuçları Çizelge 2'de verilmiştir.

Penetrasyon direnci (PD) değerlerine ait en yüksek ortalama $(0.75 \mathrm{MPa})$ ve standart sapma değeri (0.12) yüzey katmanında $(0-10 \mathrm{~cm})$ hesaplanmıştır. Standart sapma değerinin yüksek olması, PD’nin bu katmanda heterojen bir dağılım gösterdiğinin bir ölçüsüdür. Bunun yanında 31-40 cm'lik katmandan itibaren standart sapma değerlerinde kademeli olarak bir azalma görülmüştür. Üst sediment katmanındaki PD değerlerinin diğer katmanlara nazaran daha geniş bir aralıkta yer aldığı (0.62), derinlik artışına bağlı olarak bu aralığın daraldığ 1 ve en alt katmanda en düşük seviyeye indiği (0.22) belirlenmiştir. Ölçüm hatası veya uç değerlerin dağılım histogramı yardımıyla belirlenip veri setinden çıkarılmasından sonra (32 değer) yapılan normal dağılım uygunluk analizinde, tüm katmanlardaki PD değerleri normal dağılım göstermiştir (Çizelge 2).
PD değerlerinin yüzey sediment katmanında $(0-10 \mathrm{~cm})$ daha heterojen bir dağılım göstermesine başta sıcaklık olmak üzere rüzgâr ve su seviyesindeki değişimler gibi çevresel faktörlerin neden olduğu düşünülmektedir. Üst katmanda farklı derecelerde meydana gelen kurumalar, PD'nin bu katmanda daha heterojen bir dağılım göstermesiyle sonuçlanmıştır. Birikim sahasının mikro topografik yapısındaki farklılıklar, yüzey sediment katmanındaki heterojenliğin diğer bir nedeni olabilir. Mikro topoğrafyadaki değişikliklerin suyun ve rüzgârın taşıma gücünü etkileyerek taneciklerin farklı yerlerde ve farklı oranlarda birikmesine ve PD'nin de çalışma alanında önemli seviyede değişkenlik göstermesine neden olduğu düşünülmektedir. Araştırmacılar su seviyesindeki değişimlerin (Powell et al 2001; Lu et al 2010) ve rüzgârın (Zhang et al 2011), sediment birikim sahalarındaki tane büyüklük dağılımını ve bunun doğrudan bir sonucu olarak ta PD'ni (Buchanan et al 2010) etkilediğini bildirmektedirler.

\subsection{Varyans analiz sonuçları}

Çalışma alanındaki PD değerlerinin birikim katmanlarına göre önemli seviyede farklılık gösterdiği belirlenmiştir ( $\mathrm{f}=110 ; \mathrm{P}<0.01)$. Birikim katmanları arasındaki bu farklılığın derecesini belirlemek amacıyla yapılan çoklu karşılaştırma testinde, üst sediment katmanındaki $(0-10 \mathrm{~cm})$ PD'nin en yüksek seviyede olduğu $(0.75 \mathrm{MPa})$ ve derinliğe bağlı olarak bu değerin düşme eğiliminde olduğu belirlenmiştir (Şekil 3).

Çizelge 2- Her bir sediment katmanındaki penetrasyon direnci değerlerine ait istatistiksel parametreler

Table 2-Statistical parameters of penetration resistance values for each sediment layer

\begin{tabular}{lcccccccc}
\hline $\begin{array}{l}\text { Katman } \\
(\mathrm{cm})\end{array}$ & Ortalama & $\begin{array}{c}\text { Standart } \\
\text { sapma }\end{array}$ & En düşük & En yüksek & $\begin{array}{c}\text { Değişim } \\
\text { genişliği }\end{array}$ & Çarpıklık & Basılık & $\begin{array}{c}\text { Shapiro-Wilk } \\
\text { W-test }\end{array}$ \\
\hline $0-10$ & 0.75 & 0.12 & 0.45 & 1.07 & 0.62 & -0.41 & -0.19 & $0.98^{\text {od }}$ \\
$11-20$ & 0.51 & 0.09 & 0.34 & 0.76 & 0.42 & 0.07 & 1.71 & $0.97^{\text {od }}$ \\
$21-30$ & 0.47 & 0.10 & 0.32 & 0.73 & 0.41 & 0.48 & 0.15 & $0.97^{\text {od }}$ \\
$31-40$ & 0.46 & 0.11 & 0.30 & 0.82 & 0.52 & 0.48 & 0.55 & $0.96^{\text {od }}$ \\
$41-50$ & 0.44 & 0.09 & 0.31 & 0.68 & 0.37 & 0.18 & 1.12 & $0.96^{\text {od }}$ \\
$51-60$ & 0.42 & 0.07 & 0.32 & 0.64 & 0.32 & 0.24 & 1.78 & $0.97^{\text {odd }}$ \\
$61-70$ & 0.41 & 0.07 & 0.32 & 0.65 & 0.33 & 0.14 & 1.97 & $0.96^{\text {od }}$ \\
$71-80$ & 0.42 & 0.06 & 0.33 & 0.55 & 0.22 & 0.14 & 1.78 & $0.97^{\text {od }}$ \\
\hline
\end{tabular}

öd, önemli değil 


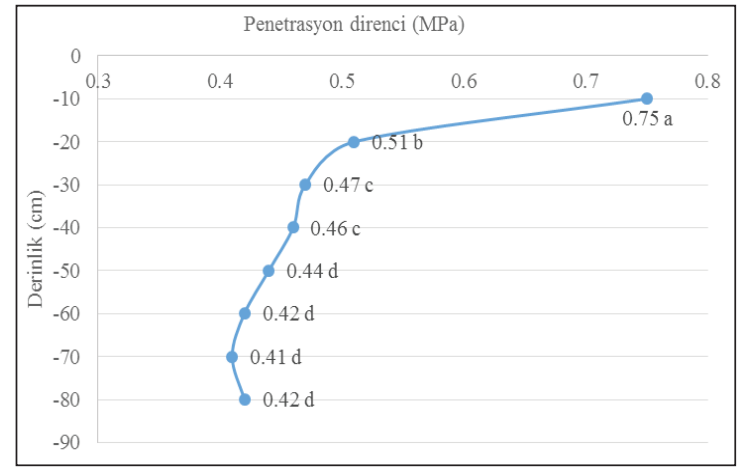

Şekil 3- LSD çoklu karşılaştırma testi sonucuna göre penetrasyon direnci değerleri bakımından katmanlar arasındaki farklılıklar (Asgari Önem Derecesi-LSD, 0.029)

Figure 3- The differences between layers in respect to the penetration resistance values according to the LSD test (Least Significance Difference-LSD, 0.029)

Oluşumu uzun yıllar alan rezervuar sedimentleri, kendi ağırlığ 1 ve yıllar itibariyle eklenen sediment miktarından dolayı zaman içerisinde sıkışma eğilimi göstermektedirler (Morris \& Fan 1998). Ancak çalışma alanındaki sediment birikim sahası yeni oluştuğundan dolayı tane dizilişleri derinlik boyunca ilk birikim koşullarını yansıtmaktadır. Morris \& Fan (1998), kil ve silt içeriği yüksek olan sedimentlerin geniş boşluk oranlarına sahip gevşek bir matris oluşturma eğiliminde olduğunu bildirmektedir. $\mathrm{Bu}$ nedenle özellikle sıcaklık gibi çevresel faktörlerin etkisinde kalmayan alt katmanların bu gevşek dizilişten dolayı düşük PD'ne sahip olması beklenen bir sonuçtur. Üst sediment katmanında PD değerlerinin yüksek çıkmasının temel nedeninin doğrudan güneş 1şığı ve rüzgâra maruz kalmasından dolayı meydana gelen nem kayıpları olduğu düşünülmektedir. $\mathrm{Bu}$ konuda yapılan çalışmalarda araştırmacılar nem içeriğindeki azalmaya bağlı olarak PD değerlerinde bir artış olduğunu bildirmektedirler (Kılıç et al 2004; Vaz et al 2011; Turgut \& Oztas 2012). Bunun yanında ıslanma-kuruma süreçlerinin üst katmanda daha etkili olması taneciklerin daha sıkı bir şekilde paketlenmesine (Dexter et al 1984; Hadas 1990) ve buna bağlı olarak PD'nin bu katmanda daha yüksek değerler almasına neden olmuştur.

\subsection{Jeoistatistiksel analiz sonuçları}

\subsubsection{Semivaryogram ve uzaysal otokorelasyonlar}

Sediment birikim katmanlarındaki PD değerleri için oluşturulan izotropik semivaryogramların jeoistatistiksel parametreleri Çizelge 3'te verilmiştir. Örnek sayısının 150'nin altında olması, PD'nin yöne bağlı olarak değişiminin (anisotropy) belirlenmesine engel olmuştur (Goovaerts 1999). Bu nedenle değişimin mesafeyle ilişkilendirildiği izotropik modeller kullanılmıştır (Şekil 4).

Çizelge 3- Her bir sediment katmanındaki penetrasyon direnci değerlerine ait semivariygram modelleri ve model parametreleri

Table 3- The semivariogram models and model parameters of penetration resistance values in each sediment layer

\begin{tabular}{clccccc}
\hline $\begin{array}{c}\text { Sediment } \\
\text { katmanı }(\mathrm{cm})\end{array}$ & Teorik model & $C_{0}$ & $C_{0}+C$ & Range $(\mathrm{m})$ & $C_{d} / C_{0}+C$ & $r^{2}$ \\
\hline $0-10 \mathrm{~cm}$ & Üssel & 0.00220 & 0.01660 & 40.80 & 0.13 & 0.753 \\
$11-20 \mathrm{~cm}$ & Üssel & 0.00420 & 0.01417 & 173.30 & 0.30 & 0.693 \\
$21-30 \mathrm{~cm}$ & Küresel & 0.00377 & 0.00852 & 136.10 & 0.44 & 0.842 \\
$31-40 \mathrm{~cm}$ & Küresel & 0.00424 & 0.01158 & 102.70 & 0.37 & 0.837 \\
$41-50 \mathrm{~cm}$ & Küresel & 0.00129 & 0.00848 & 106.40 & 0.15 & 0.778 \\
$51-60 \mathrm{~cm}$ & Küresel & 0.00101 & 0.00590 & 114.90 & 0.17 & 0.829 \\
$61-70 \mathrm{~cm}$ & Küresel & 0.00140 & 0.00756 & 96.20 & 0.19 & 0.717 \\
$71-80 \mathrm{~cm}$ & Küresel & 0.00088 & 0.00462 & 100.40 & 0.19 & 0.719 \\
\hline
\end{tabular}

$\mathrm{C}_{0}$, nugget varyans; $\mathrm{C}$, yapı bileşeni; $\mathrm{r}^{2}$; modele ait regresyon katsayısı 

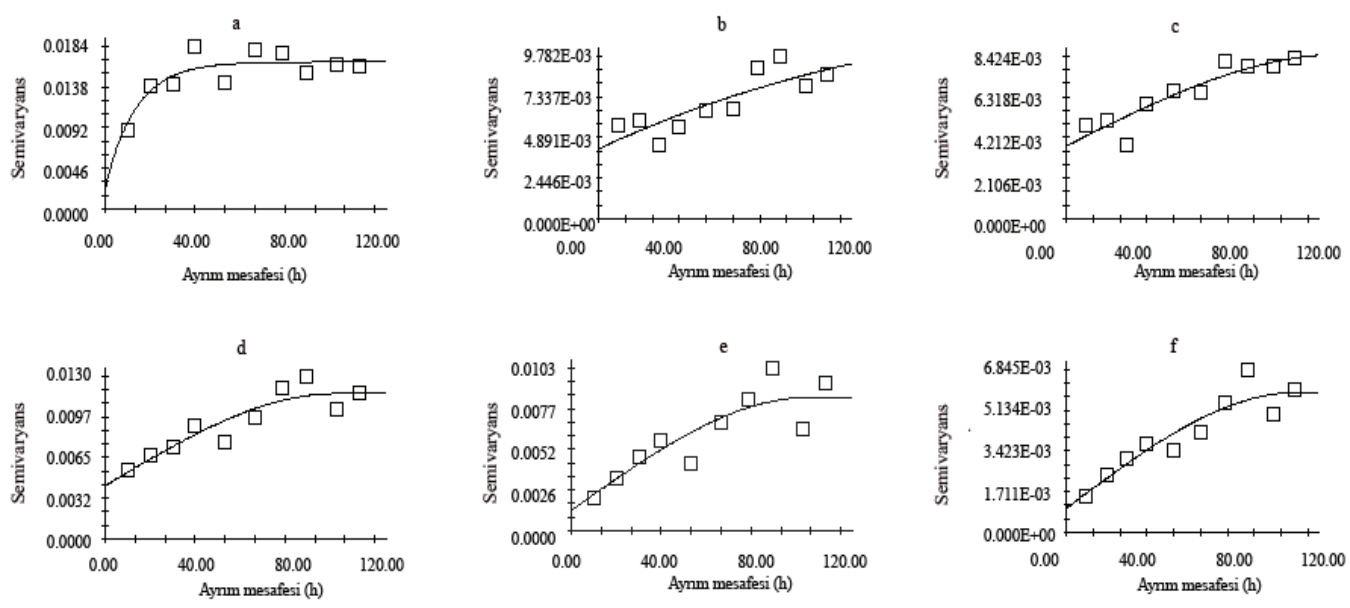

g
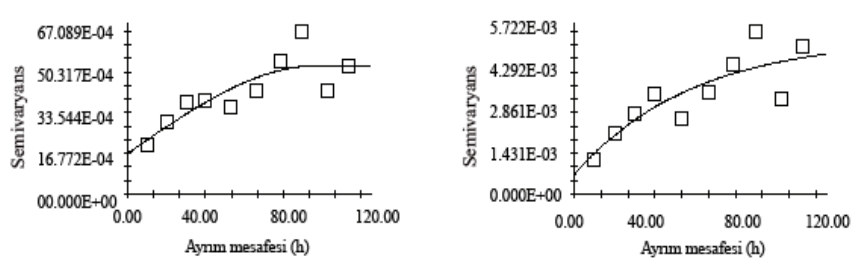

Şekil 4- Sediment katmanlarındaki (a, 0-10 cm; b, 10-20 cm; c, 20-30 cm; d, 30-40 cm; e, 40-50 cm; f, 50-60 $\mathrm{cm} ; \mathrm{g}, \mathbf{6 0 - 7 0} \mathrm{cm} ; \mathbf{h}, 70-80 \mathrm{~cm}$ ) penetrasyon direnci değerlerine ait semivaryogram modelleri

Figure 4- The semivariogram models of penetration resistance values in the sediment layers $(a, 0-10 \mathrm{~cm} ; \mathrm{b}, 10-20$ $\mathrm{cm} ; \mathrm{c}, 20-30 \mathrm{~cm} ; d, 30-40 \mathrm{~cm} ; \mathrm{e}, 40-50 \mathrm{~cm} ; f, 50-60 \mathrm{~cm} ; \mathrm{g}, 60-70 \mathrm{~cm} ; \mathrm{h}, 70-80 \mathrm{~cm})$

Model parametreleri incelendiğinde nugget değerlerinin $11-20 \mathrm{~cm}(0.00420), 21-30 \mathrm{~cm}(0.00377)$ ve $31-40 \mathrm{~cm}(0.00424)$ derinliğindeki katmanlarda daha yüksek olduğu görülmüştür. Diğer bir ifadeyle bu katmanlarda iki nokta arasındaki mesafenin sıfir olduğu durumda bile bir değişkenlik ortaya çıkmıştır. $\mathrm{Bu}$ değişkenliğin kaynakları ölçüm ya da örnekleme hatası (Jemo et al 2014; Oliver \& Webster 2014), incelenen özelliğin örnekleme aralığından daha kısa mesafelerde değişkenlik göstermesi ve çalışma alanının doğasında var olan değişkenliktir (Jemo et al 2014). Söz konusu katmanlarda açıklanamayan değişkenliğin nedeninin, sıkışma anlamında henüz dengeye ulaşmamış sedimentlerin kendisini meydana getiren materyallerin farklı orijinlere sahip olmasından kaynaklanan doğal değişkenlik olduğu düşünülmektedir. Değişkenliğin uzaysal bağımlılı̆̆ının (otokorelasyon) bir göstergesi olan nugget/sill oranının $\left(\mathrm{C}_{0} / \mathrm{C}_{0}+\mathrm{C}\right), \% 25$ 'in altında olması uzaysal bağımlılığın kuvvetli, \% 25-75 arasında olması orta ve $\% 75$ 'den büyük olması ise zayıf olduğunu göstermektedir (Li \& Reynolds 1995; Chien et al 1997). Çalışma sahasının 11-20 cm, 21$30 \mathrm{~cm}$ ve $31-40 \mathrm{~cm}$ 'lik katmanlarındaki $\mathrm{C}_{0} / \mathrm{C}_{0}+\mathrm{C}$ değerlerinin sirasiyla $0.30,0.44$ ve 0.37 olduğu, bu nedenle söz konusu katmanlarda ölçülen PD'ndeki değişimin orta düzeyde uzaysal bağımlılık gösterdiği belirlenmiştir. Diğer yandan $41-50 \mathrm{~cm}$ derinliğindeki katmandan itibaren, ölçülen özellik yüksek düzeyde uzaysal bağımlılık göstermiştir. Semivaryogramlarda belirlenen diğer bir model parametresi ise range değeridir. Oliver \& Webster (2014) range değeri içerisinde kalan noktaların birbirleriyle ilişkili 
olduğu, bu değerin dışındaki mesafelerde kalan noktaların ise uzaysal olarak bağımsız olduğunu bildirmektedirler. Bu çalışmada sediment katmanları içerisinde en düşük range değeri $(40.80 \mathrm{~m})$, standart sapma değerinin en yüksek olduğu yüzey katmanında $(0-10 \mathrm{~cm})$ hesaplanmıştır. Cambardella et al (1994) range değerinin aktif lag mesafesinden büyük olması durumunda örnek sayısının uzaysal bağımlılığın tahmin edilmesi için yetersiz olduğunu bildirmektedir. Çalışmada $21-30 \mathrm{~cm}$ ve $31-40 \mathrm{~cm}$ 'lik katmanlar için hesaplanan range değerlerinin (sırasıyla $173.30 \mathrm{~m}$ ve $136.10 \mathrm{~m})$ aktif lag mesafesinden $(120 \mathrm{~m})$ yüksek olması nedeniyle söz konusu katmanlardaki örnekleme sayısının (91) yetersiz olduğu sonucuna varılmıştır.

\subsubsection{Krigleme ve penetrasyon direnç değerlerinin uzaysal dăğlımı}

Çalışma alanındaki sediment birikim katmanlarının daha iyi karşılaştırılabilmesi için dağılım haritalarında sınıf aralıkları her katmanda aynı alınmıştır. Kriging interpolasyon yöntemi ile oluşturulan PD değerlerine ait tahmin haritaları incelendiğinde yüzey katmanının $(0-10 \mathrm{~cm})$ diğer katmanlardan farklı bir dağ $11 \mathrm{~m}$ gösterdiği görülmüştür. PD yüzey katmanında 0.510 MPa'nın altına düşmezken alt katmanlarda ise 0.650 MPa'nın üzerine çıkmamıştır (Şekil 5). PD yüzey katmanında daha yüksek değerlerler alsa da range değerinin daha düşük olmasının bir sonucu olarak,
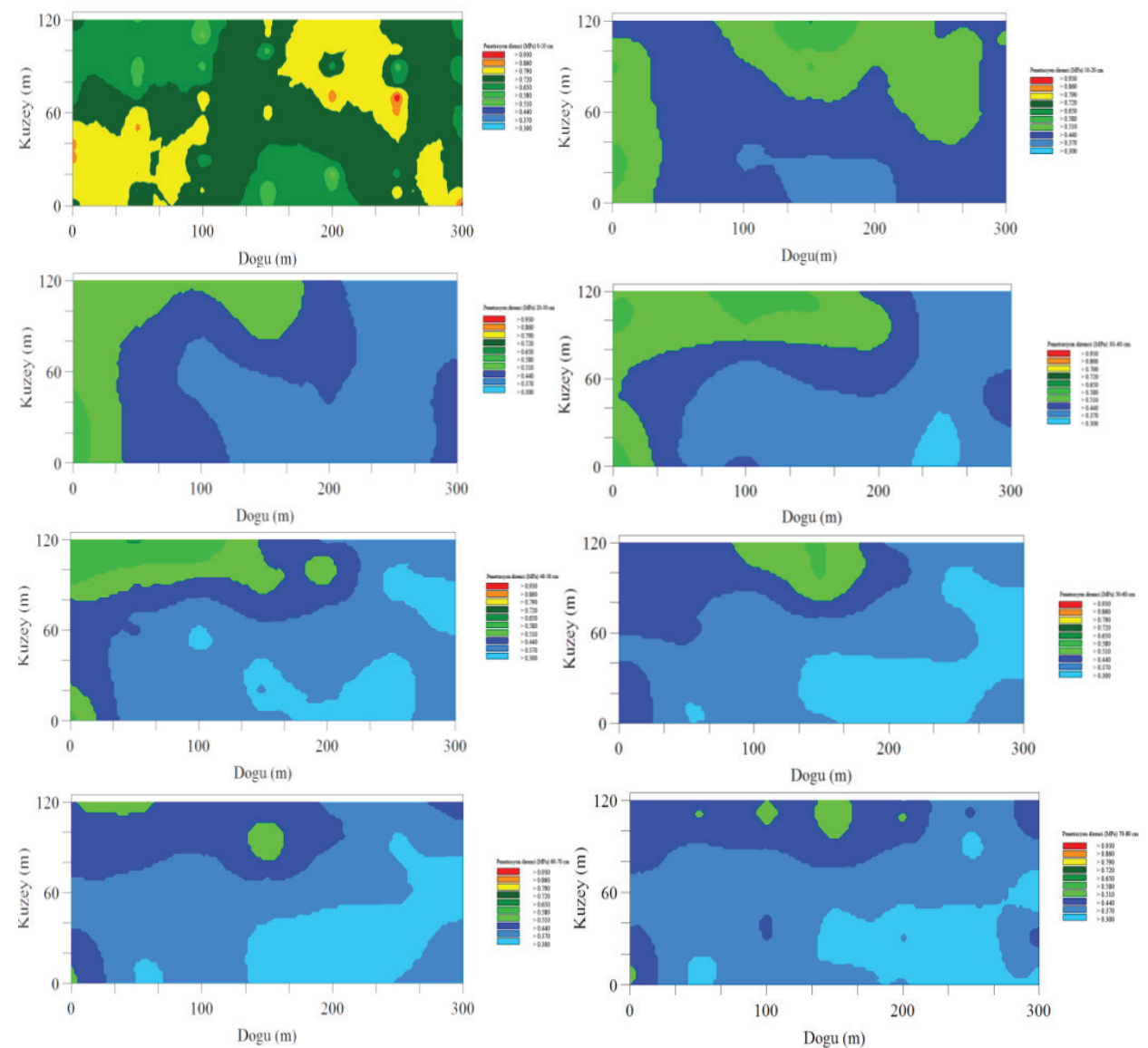

Şekil 5- Sediment katmanlarındaki penetrasyon direnci değerlerinin uzaysal dağılım haritaları

Figure 5- The spatial distribution maps of penetratin resistance values in the sediment layers 
dağılım haritasında alt katmanlardaki gibi kademeli değişimler yerine ani yükselmeler ve düşmeler görülmüştür.

Her ne kadar örnek sayısının yetersizliğinden dolayı değişimin yönle ilişkisi (anisotropy) incelenememiş olsa da alt katmanlarda PD'nin kuzeygüney ve doğu-batı yönlerinde bir artış eğiliminde olduğu fakat yüzey katmanında bu eğilimin net olarak görülmediği belirlenmiştir. Deriner barajının su tutmaya başlamasına kadar geçen süre içerisinde sediment birikimi rezervuar gölü tabanında meydana gelmiştir, ancak rezervuar sahasındaki su seviyesinin düşmesiyle beraber birikim sahaları yüzeye çıkarak çevresel faktörlerin etkisi altında kalmış ve bu durumdan en fazla etkilenen kısım ise yüzey katmanı olmuştur. Bu nedenle yüzey katmanındaki sedimentler birikim koşullarını yansıtan özelliklerini kaybetmiş, ancak çevresel faktörlerden daha az etkilenen alt katmanlar bu özelliklerini yansıtmaya devam etmişlerdir. Sediment birikim sahalarında nehir yatağına doğru gidildikçe biriken materyalin ortalama çap değerlerinin (Morris \& Fan 1998) ve buna bağlı olarak PD değerlerinin arttığ (Buchanan et al 2010; Ecemis \& Karaman 2014) bilinmektedir. Çalışma alanının güney ve batı kısımları nehir yatağına daha yakın olmasından dolayı bu alanlarda biriken materyalin daha iri parçacıklardan oluşması, alt katmanlarda PD değerlerinin bu alanlarda yüksek çıkmasını açıklamaktadır.

PD değerlerine ait ölçüm değerleri ile krigleme sonucunda elde edilen tahmin değerlerinin ortalama ve standart sapma değerleri Çizelge 4'te verilmiştir. Her bir katmandaki ortalama PD'nin farklılık göstermediği, ancak krigleme sonucunda elde edilen verilerin standart sapma değerlerinin daha düşük olduğu belirlenmiştir. Tahmin edilen değerler ile ölçüm değerleri arasındaki korelasyon katsayısı bu değerlerin $45^{\circ}$ hat boyunca birbirlerinden ne ölçüde farklılık gösterdiğinin iyi bir göstergesidir (Ersahin \& Brohi 2006). Bu amaçla yapılan değerlendirmelerde korelasyon katsayısının 0-10 $\mathrm{cm}$ derinliğindeki katmanda 0.47 ve $11-20 \mathrm{~cm}$ 'lik katmanda ise 0.54 olarak hesaplanmıştır, ancak 21-30 cm'lik katmandan itibaren korelasyon katsayısının 0.70 'in üzerinde olduğu belirlenmiştir. Elde edilen bulgular, yeni birikmiş sedimentlere ait PD'nin uzaysal dağılımlarının belirlenmesinde mevcut örnekleme mesafelerinin $(50 \mathrm{~m}$ x $10 \mathrm{~m})$ ilk iki katman için yetersiz olduğunu yani örnekleme mesafesinin daha kısa tutulması gerektiğini, üçüncü katmandan itibaren ise söz konusu örnekleme mesafesinin yeterli olduğunu göstermektedir.

\section{Çizelge 4- Ölçülen ve modelde tahmin edilen değerlerin karşılaştırmaları}

Table 4-Comparison of actual and estimated values

\begin{tabular}{|c|c|c|c|c|c|}
\hline \multirow{2}{*}{$\begin{array}{l}\text { Değişken } \\
(\mathrm{cm})\end{array}$} & \multicolumn{2}{|c|}{ Ortalama } & \multicolumn{2}{|c|}{ Standart sapma } & \multirow{2}{*}{$r^{a}$} \\
\hline & Ölçülen & Tahmin edilen & Ölçülen & Tahmin edilen & \\
\hline $0-10$ & 0.75 & 0.75 & 0.12 & 0.04 & 0.47 \\
\hline $11-20$ & 0.51 & 0.51 & 0.09 & 0.05 & 0.54 \\
\hline $21-30$ & 0.47 & 0.47 & 0.10 & 0.06 & 0.73 \\
\hline $31-40$ & 0.46 & 0.46 & 0.11 & 0.07 & 0.75 \\
\hline $41-50$ & 0.44 & 0.44 & 0.09 & 0.07 & 0.82 \\
\hline $51-60$ & 0.42 & 0.42 & 0.07 & 0.05 & 0.86 \\
\hline $61-70$ & 0.41 & 0.41 & 0.07 & 0.05 & 0.80 \\
\hline $71-80$ & 0.42 & 0.42 & 0.06 & 0.05 & 0.86 \\
\hline
\end{tabular}

a, çapraz doğrulama korelasyon katsayısı

\section{Sonuçlar}

Mevcut enerji yatırımları programı kapsamında Çoruh nehri üzerinde on adet baraj ve hidroelektrik santrali planlanmaktadır. Bunlardan ilk üç tanesi (Muratlı, Borçka ve Deriner Barajları) tamamlanarak enerji üretimine başlamıştır. Ancak, barajların 
ekonomik ömrünü önemli ölçüde etkileyen sediment özelliklerinin belirlenmesi ile ilgili şu ana kadar herhangi bir çalışma yapılmamıştır. Bu çalışma söz konusu alanda sediment birikimi ile ilgili ilk çalışma olma niteliğindedir. Su tutmaya başladığı 2007 yılından beri Borçka Barajı Rezervuar sahasında önemli seviyede sediment birikimi gerçekleşmiştir. Özellikle mevsime bağlı su seviyesindeki düşmelerle bu birikintiler rezervuar sahası boyunca kendini göstermektedir. Biriken sedimentin büyük bir kısmının ince yapılı olduğu ve yılın belirli dönemlerinde bu birikim sahalarının su altında kaldı̆̆ı gözlemlenmiştir.

Sediment katmanlarındaki penetrasyon direnci (PD) değerlerine ait tanımlayıcı istatistikler incelendiğinde, yüzey sediment katmanının hem en yüksek ortalama PD değerine sahip olduğu hem de incelenen özellik bakımından en heterojen katman olduğu görülmüştür.

PD bakımından sediment katmanları arasındaki farklılığın belirlenmesinde varyans analizi kullanılmıştır. Analiz sonuçları PD'nin yüzey katmanında en yüksek değer aldığını, beklenenin aksine derinliğe bağlı olarak önemli seviyede düşme eğiliminde olduğunu göstermiştir.

PD değerlerinin uzaysal değişimi jeoistatistiksel yöntemler kullanılarak belirlenmiştir. Semivaryogram analizleri sonucunda model parametrelerinin her bir katmanda farklı olduğu, örnekleme noktaları arasındaki varyansın mesafeye bağlı olarak değişkenlik sergilediği ve PD değerlerinin yüzey sediment katmanı dışındaki tüm katmanlarda nehre dik doğrultuda artış gösterdiği belirlenmiştir. Modellemelerin güvenilirliklerinin sorgulandığ 1 çapraz doğrulama testlerinde ise uygulanan krigleme yönteminin (blok kriging) ilk iki katmanda $(0-10 \mathrm{~cm}$ ve $11-20 \mathrm{~cm}$ ) güvenilir sonuçlar vermediği ancak üçüncü katmandan $(21-30 \mathrm{~cm})$ itibaren modelin güvenilirliğinin arttığı görülmüştür.

Benzer çalışmaların daha fazla değişkenle rezervuar sahasındaki diğer sediment birikim sahalarında yürütülmesi ile hem rezervuar sahasının geneli hakkında hem de bu alanlardaki uzaysal değişkenliğin gelişim derecesinde etkili mekanizmaların anlaşılması noktasında yararlı olacağı düşünülmektedir.

\section{Kaynaklar}

Akıncı H, Yavuz Özalp A \& Turgut B (2013). Agricultural land use suitability analysis using GIS and AHP technique. Computers and Electronics in Agriculture 97: 71-82

Arega F \& Hayter E (2008). Coupled consolidation and contaminant transport model for simulating migration of contaminants through the sediment and a cap. Applied Mathematical Modelling 32: 2413-2428

Bravard J-P, Goichot M \& Tronchère H (2014). An assessment of sediment-transport processes in the Lower Mekong River based on deposit grain sizes, the $\mathrm{CM}$ technique and flow-energy data. Geomorphology 207: 174-189

Buchanan S J, So H B, Kopittke P M \& Menzies N W (2010). Influence of texture in bauxite residues on void ratio, water holding characteristics, and penetration resistance. Geoderma 158: 421-426

Cabezas A, Angulo-Martínez M, Gonzalez-Sanchís M, Jimenez J J \& Comín F A (2010). Spatial variability in floodplain sedimentation: The use of generalized linear mixed-effects models. Hydrology and Earth System Science 14: 1655-1668

Cambardella C A, Moorman T B, Novak J M, Parkin T B, Karlen D L, Turco R F \& Konopka A E (1994). Field-scale variability of soil properties in central Iowa soils. Soil Science Society of America Journal 58: $1501-1511$

Chien Y J, Lee D Y, Guo H Y \& Houng K H (1997). Geostatistical analysis of soil properties of mid-west Taiwan soils. Soil Science 162: 291-297

Conklin A R (2005). Introduction to Soil Chemistry: Analysis and Instrumentation. Wiley, Hoboken NJ, USA

Dane J H, Topp C, Campbell G S, Horton R, Jury W A, Nielsen D R, van Es H M, Wierenga P J \& Topp G C (2002). Methods of Soil Analysis: Part 4-Physical methods. Soil Since Society of America, Inc, Madison WIS, USA

de Groot A V, Veeneklaas R M, Kuijper D P J \& Bakker J P (2011). Spatial patterns in accretion on barrierisland salt marshes. Geomorphology 134: 280-296

Dexter A R, Kroesbergen B \& Kuipers H (1984). Some mechanical properties of aggregates of top soils from the Ijsselmeer polders. 2: Remolded soil aggregates and the effects of wetting and drying cycles. Netherlands Journal of Agricultural Sciences 32: 215-227 
Ecemis N \& Karaman M (2014). Influence of non-/low plastic fines on cone penetration and liquefaction resistance. Engineering Geology 181: 48-57

Ersahin S \& Brohi A R (2006). Spatial variation of soil water content in topsoil and subsoil of a Typic Ustifluvent. Agricultural Water Management 83: 79-86

Gamma Design Software (2014). GS+Version 10. Geostatistics for the Environmental Sciences User's Guide. Gamma Design Software, LLC

Gee G W \& Bauder J W (1986). Particle-Size Analysis. In: A Klute (Ed), Methods of Soil Analysis. Part 1. Physical and Mineralogical Methods, Soil Since Society of America, Inc. Madison WIS, USA

Goovaerts P (1999). Geostatistics in soil science: Stateof-the-art and perspectives. Geoderma 89: 1-45

Hadas A (1990). Directional strength in aggregates as affected by aggregate volume and by a wet/dry cycle. Journal of Soil Science 41: 85-93

Jemo M, Jayeoba O J, Alabi T \& Montes A L (2014). Geostatistical mapping of soil fertility constraints for yam based cropping systems of North-central and Southeast Nigeria. Geoderma Regional 2-3: 102-109

Journel A G \& Huijbregts C J (1978). Mining Geostatistics. Academic press, Berkeley CA, USA

Kamarudin M K A, Toriman M E, Mastura S, Idris M H, Jamil N R \& Gasim M B (2009). Temporal variability on lowland river sediment properties and yield. American Journal of Environmental Science 5: 657-663

Kılıç K, Özgöz E \& Akbaş F (2004). Assessment of spatial variability in penetration resistance as related to some soil physical properties of two fluvents in Turkey. Soil and Tillage Research 76: 1-11

Li H B \& Reynolds J F (1995). On definition and quantification of heterogeneity. Oikos 73: 280-284

Lu Y, Zuo L, Ji R \& Liu H (2010). Deposition and erosion in the fluctuating backwater reach of the Three Gorges Project after upstream reservoir adjustment. International Journal of Sediment Research 25: 64-80

Montgomery D C, Peck E A \& Vining G G (2012). Introduction to Linear Regression Analysis. Wiley Press, New York

Morris G L \& Fan J (1998). Reservoir Sedimentation Handbook: Design and Management of Dams, Reservoirs, and Watersheds for Sustainable Use. McGraw-Hill Press, New York

Mulvaney R L (1996). Nitrogen-inorganic forms. In: D L Sparks, A L Page, P A Helmke, R H Loeppert, P N Soltanpoor, M A Tabatabai, C T Johnston \& M E Sumner (Eds), Methods of Soil Analysis. Part 3. Chemical Methods, SSSA Book Series, Vol. 5, Soil Science Society of America, Inc.; American Society of Agronomy, Inc., Madison
Narantsetseg B, Kim G Y, Kim J-W, Chang T S, Lee G S, Choi H \& Kim S-P (2014). Physical property variations related to seismic units in the offshore sediments of the Heuksan Mud Belt, Southeastern Yellow Sea, Korea. Quaternary International 344: 97-108

Oliver M A \& Webster R (2014). A tutorial guide to geostatistics: Computing and modelling variograms and kriging. Catena 113: 56-69

Pekal K \& Tilki F (2010). Evaluation of plantations along Artvin Çoruh River Basin: A case study in Sumbullu and Salkimli districts. Proceedings of the $3^{\text {th }}$ National Black Sea Forestry Congress, 20-22 May, Artvin, Turkey, pp. 656-667

Powell D M, Reid I \& Laronne J B (2001). Evolution of bed load grain size distribution with increasing flow strength and the effect of flow duration on the caliber of bed load sediment yield in ephemeral gravel bed rivers. Water Resources Research 37: 1463-1474

Sucu S \& Dinç T (2008). Çoruh Havzası Projeleri. TMMOB 2. Su Politikalart Kongresi, 21-23 Mart, Ankara, Türkiye, Cilt: 1, s. 33-38

Turgut B \& Oztas T (2012). Spatial variation in some soil properties influencing penetration resistance. Tarim Bilimleri Dergisi-Journal of Agricultural Sciences 18: $115-125$

Vaz C M P, Manieri J M, de Maria I C \& Tuller M (2011). Modeling and correction of soil penetration resistance for varying soil water content. Geoderma 166: 92-101

Walling D E \& Moorehead P W (1989). The particle size characteristics of fluvial suspended sediment: An overview. Hydrobiologa 176-177: 125-149

Webster R \& Oliver M A (1992). Sample adequately to estimate variograms of soil properties. Journal of Soil Science 48: 173-175

Xu J (2000). Grain-size characteristics of suspended sediment in the Yellow River, China. Catena 38: 243263

Yavuz Özalp A, Akıncı H \& Temuçin S (2013). Artvin ili arazisinin topografik ve bazı fiziksel özelliklerinin tespiti ve bu özelliklerin arazi örtüsü ile ilişkisinin incelenmesi. Artvin Çoruh Üniversitesi Orman Fakültesi Dergisi 14(2): 292-309

Zengin M, Özer S \& Özgül M (2009). Determining of erosion situation of the Coruh Watershed by GIS and solution suggestions. Atatürk University Journal of the Faculty of Agriculture 40: 9-19

Zhang J, Zhang C, Zhou N \& Ma X (2011). Spatial pattern of grain-size distribution in surface sediments as a result of variations in the aeolian environment in China's Shapotou railway protective system. Aeolian Research 3: 295-302 